\title{
DOIS MINEIROS NO MEIO DE CAMPO CARIOCA: REFLEXÕES ACERCA DA DIALOGIA ENTRE CRÔNICAS DE DRUMMOND E CAMPOS
}

\author{
TWO MINERS IN MIDFIELD RIO: REFLECTIONS ON DIALOGIC BETWEEN \\ CHRONIC DRUMMOND AND CAMPOS
}

\author{
Eliane Aparecida Galvão Ribeiro Ferreira ${ }^{1}$ \\ Ricardo Magalhães Bulhões ${ }^{2}$
}

\begin{abstract}
Resumo
Este texto tem por objetivo analisar duas crônicas: "Pelé, o Mágico", de Drummond, e "Mané Garrincha”, de Mendes Campos. Esses textos, embora tenham sido retirados de obras diversas, respectivamente, Quando é dia de futebol (2006); e O Gol é necessário: crônicas esportivas (2008), ambos tratam de um mesmo tema: futebol. Para tanto, buscamos levantar relações de reciprocidade entre essas duas obras, sempre na procura das possíveis afinidades temático-estilísticas presentes na ficção dos dois autores. Mais especificamente, pretendemos apresentar os dois livros para, em seguida, analisar as duas crônicas, tendo em vista que se aproximam, também, pelo "alumbramento" que manifestam em relação ao futebol e pela abordagem metalinguística que conferem ao tema. Para a consecução do objetivo, adotamos uma perspectiva comparativa.
\end{abstract}

Palavras-chave: Crônica. Perspectiva comparativa. Futebol.

\begin{abstract}
This text aims to analyze two chronicles: Drummond's "Pelé, the Wizard", and Campos’s "Mané Garrincha”. These texts, although they have been taken from various works, respectively, When the day is football (2006); and The Goal is needed: chronic sports (2008), both dealing with the same theme: Soccer. Therefore, we seek to raise reciprocal relationships between these two works, always in search of possible thematic-stylistic affinities present in the fiction of both authors. More specifically, we intend to present the two books, then analyze the two chronicles, considering that approach, too, by dazzle that manifest in relation to football and metalinguistic approach by giving the theme.
\end{abstract}

Keywords: Chronicle. Comparative perspective. Football.

\footnotetext{
${ }^{1}$ Professor Adjunto da Fundação Educacional do Município de Assis (FEMA). Doutor em Letras pela Universidade Estadual de São Paulo, Câmpus de Assis (Unesp-Assis). Membro de GP CRELITUENP-CP. Assis-SP, Fundação Araucária, Pesquisador do projeto “A Leitura e os jovens leitores: Práticas de letramento no Norte Pioneiro-PR”, Brasil, eagrf@femanet.com.br

2 Professor Adjunto na Universidade Federal de Mato Grosso do Sul, em Três Lagoas, onde atua na Graduação em Letras e no Mestrado em Estudos Literários. Graduação em Letras (1986), Mestrado em Letras (1992) e Doutorado em Letras (2007), todos pela Universidade Estadual Paulista Júlio de Mesquita Filho - Unesp/Assis. E-mail: lbulhoes@femanet.com.br
} 


\section{Introdução}

Os mineiros, Carlos Drummond de Andrade e Paulo Mendes Campos, exerceram durante longo período atividade jornalística. Ambos publicaram crônicas com temas e estilos diversos. Diante dessa diversidade, nosso recorte recai sobre duas crônicas: "Pelé, o Mágico", de Drummond, e "Mané Garrincha”, de Mendes Campos, que, embora sejam retiradas respectivamente de livros diversos - Quando é dia de futebol (2006); e O Gol é necessário: crônicas esportivas (2008) -, tratam de um mesmo tema: futebol.

Para nortear nossa discussão, este texto tem por objetivo geral levantar relações de reciprocidade entre as duas obras, sempre à procura das possíveis afinidades temático-estilísticas presentes na ficção dos dois autores. Mais especificamente, pretendemos apresentar as duas obras para, em seguida, analisar as duas crônicas, tendo em vista que se aproximam pela temática, pelo “alumbramento” que manifestam em relação ao futebol e pela abordagem metalinguística que conferem ao tema. Justifica-se a nossa escolha por crônicas recolhidas e publicadas em livro, pois esse gênero, quando publicado nesse formato, revela sua atemporalidade, rompendo com o imediatismo da notícia de jornal que lhe dera origem.

Segundo Iser (1999), uma obra antevê um leitor implícito, ou seja, o trabalho ficcional define-se pela intenção de quem escreve em relação a seu destinatário. À primeira vista, no correr da leitura das duas obras, é possível verificar que os cronistas deixam a realidade que os cerca para traçarem comentários subjetivos que, voltados para o leitor sob a forma de um diálogo espontâneo, visam a cativá-lo e, justamente por isso, enredá-lo na leitura.

Ao tratar de Drummond como cronista, Pires (2008) salienta que este põe de lado a estruturação narrativa da maioria de suas crônicas, para ceder, poeticamente, a palavra ao inquieto e reflexivo eu-lírico. Como este escritor, Mendes Campos também apresenta um olhar crítico em suas narrativas. Embora estas revelem uma postura intimista, diferem das de Drummond, pois mantêm a tônica do humor e da leveza. Tanto Drummond quanto Mendes Campos revelam-se como perspicazes observadores da realidade social em que vivem. Ambos são capazes de descobrir, nos fatos cotidianos e nas circunstâncias da vida, beleza, humor e ironia. A representação da realidade em seus 
textos aparece refinada pela habilidade em lidar com as palavras, estas, por sua vez, surgem decantadas em criação literária.

Para a consecução dos objetivos, adotamos uma perspectiva comparatista, buscando certas afinidades entre as obras e as crônicas mencionadas, seguindo como princípio norteador a ideia de Moisés (2005) de que essas relações podem ser estudadas entre: obras, autores, movimentos; por meio de análises da fortuna crítica ou da fortuna de tradução de um autor em outro país, do estudo de um tema ou de uma personagem em várias literaturas. Embora publicadas em meios diversos, as crônicas de Drummond e Campos pertencem, originalmente, ao mesmo campo cultural (BOURDIEU, 2004). Dessa forma, as negociações e os consensos que surgem representados no texto literário de ambos dialogam tanto com a realidade circundante, quanto com a produção literária do seu tempo e com a canônica. Pelo exposto, cabe refletir, então, acerca da dialogia que se estabelece nas obras e crônicas desses escritores, e entre elas. Como está representada a realidade em seus textos? Sobretudo, como se configura o tema futebol?

Analisa-se, neste texto, o dialogismo discursivo interno, no âmbito do texto, das vozes que falam e polemizam nele, reproduzindo o diálogo com outros textos (BARROS, 1999). Neste artigo, parte-se do pressuposto de que a explicitação da dialogia entre obras permite que a leitura se torne mais interessante e saborosa para o leitor, pois, conforme Eco (2003, p.212), ele percebe a “piscadela do texto”, a citação intertextual presente no jogo ficcional. Conforme Rodrigues (2003), o dialogismo enaltece o papel do outro na constituição do sentido. Por meio dele, pode-se reconhecer que a palavra não pertence a um "eu” exclusivo, antes traz em si a perspectiva de outra voz (BAKHTIN, 1995). Desse modo, buscamos analisar o texto literário tanto em seu caráter artístico, quanto em sua historicidade, pela relação dialógica que estabelece com o leitor. Essa relação, conforme a estética da recepção, decorre da presença de vazios que solicitam do leitor um papel na composição literária: o de organizador e revitalizador da narrativa. Assim, o texto, por supor necessariamente um recebedor, possui uma estrutura de apelo que invoca a participação de um indivíduo na feitura e acabamento: é seu leitor implícito (ISER, 1999).

\section{No meio de campo com Drummond}


Quando é dia de futebol resulta de uma coletânea de textos em torno deste tema, organizada pelos seus netos: Luis M. G. Drummond e Pedro A. G. Drummond. Entre os textos de Carlos Drummond de Andrade, aparecem crônicas publicadas desde a juventude, em sua maioria, nos jornais Correio da Manhã (entre 1954 e 1969) e Jornal do Brasil (entre 1969 e 1984), poemas, epígrafes, textos jornalísticos, e fragmentos de cartas enviadas à filha e aos netos. A seleção apresenta textos escritos ao longo de mais de 50 anos sobre o futebol brasileiro. Em sua estruturação, o livro possui 18 partes. Dessas, nove seções são ordenadas em torno das Copas do Mundo, de 1954 a 1986. Suas crônicas questionam a ilusória sensação de ser campeão, abordam a problemática do nervosismo do torcedor e alertam para outras belezas simples da vida, das quais ele se esquece em época de Copa. Por meio de relações intertextuais, elas discorrem sobre as estratégias do governo que se utiliza do futebol como instrumento alienante. Em um exercício crítico e metalinguístico, abordam o paradoxal papel do cronista que, embora não entenda de política e futebol, precisa escrever sobre eles.

Ao término dessas seções, aparecem cinco partes. Uma, dedicada a Pelé, apresenta os encantamentos que esse jogador é capaz de produzir pela sua competência e lição de humildade. Outra, dedicada a Garrincha, realiza tanto uma crítica aos governantes do povo e do futebol, quanto ao torcedor que sufoca o jogador, exigindo espetáculo para se esquecer da tristeza. Os textos desta enaltecem as habilidades desse jogador, ao mesmo tempo em que o apresentam como uma vítima de um sistema corruptor e destruidor. Outras duas partes, dispostas como epílogo, possuem trechos de cartas que Drummond escreveu à filha e aos netos. Esses textos revelam-no como um escritor sensível aos problemas sociais, um pai dedicado, avô participante, dotado de senso crítico, que se utiliza da escrita como instrumento de manifestação de suas crenças, indignações e amores, ainda de conscientização do leitor. A parte final, em linguagem jornalística, apresenta Drummond e sua produção, além do próprio livro.

Dotado de bom projeto gráfico-editorial, Quando é dia de futebol organiza seus textos de forma complementar e dialógica em torno do futebol. No final do livro, o índice remissivo dos textos sinaliza para o leitor em quais jornais eles foram originalmente publicados ou em quais obras. A quarta capa complementa a primeira no uso das cores e da imagem. Composta pelo nome completo de Drummond e um fragmento da crônica "Jogo à distância”, conota um diálogo instigante do escritor com o 
leitor. Esse fragmento, seguido por um site, revela que se antevê um público internauta e curioso, que, provavelmente, buscará, motivado pelas leituras, novas informações sobre o escritor e sua produção.

\section{No meio de campo com Mendes Campos}

O Gol é necessário: crônicas esportivas (2008) trata-se, também, de um livro composto por uma coletânea de crônicas, de Paulo Mendes Campos, sobre futebol. A bibliografia e biografia deste escritor classificam-no como um dos maiores cronistas do país em um período no qual coexistiam autores da qualidade de Fernando Sabino, Rubem Braga, Carlos Drummond de Andrade, entre outros (2008, p. 9). O projeto editorial é coerente e adequado, pois permite ao leitor conhecer e apreciar as crônicas de Mendes Campos que tratam do esporte e, com isso, apresentar ainda as que são inéditas. A coletânea traz, em sua maioria, textos publicados na revista Manchete, conforme uma organização temporal que começa na década de 1950, com o surgimento de Garrincha, e vai até a Copa do Mundo de 1974. Apesar de datados, os textos apresentam um excelente trabalho com a linguagem que lhes permite, por meio do humor, suscitar reflexões no leitor.

A crônica de Paulo Mendes Campos, mesmo para quem nunca ouviu falar de Garrincha, Didi, Nilton Santos ou Ademir da Guia, diverte, emociona e permite ao leitor ampliar seus conhecimentos, ao estabelecer relações com outros autores, como Stendhal, Balzac, Flaubert, Dostoievski, Rilke e Fröebel. Nos textos “Círculo Vicioso 1959” (2008, p. 47), “Vai da Valsa” (2008, p. 49), e "Poesia é necessária, mas foi Frango” (2008, p. 91), o autor passa a retratar o cotidiano através da poesia: “[...] versos ingênuos, mas sinceros...” (2008, p. 49). No final do livro, sob o título “Coriscos”, o organizador traz frases e períodos que destacam a verve frasista de Mendes Campos: "O pugilista dá socos à procura de paz” (2008, p. 93).

O projeto editorial, assinado pelos designers, Grumach e Leite, é bem-sucedido e adequado à temática. A ilustração de capa remete ao conteúdo da publicação. A distribuição das cores e dos espaços da capa é, por seu turno, clássica. O quadro laranja que traz o nome do autor, a ilustração do time de futebol e o nome do livro ocupam dois terços da página, enquanto fica livre um terço onde está o quadro vermelho e os quadros 
amarelos, que contêm o nome da editora. Esta distribuição clássica serve para remeter o leitor a um tema também constante através dos tempos nos debates no Brasil: o futebol. Enfim, trata-se de uma obra agradável à leitura.

\section{O jogo entre Drummond e Campos}

Feita a apresentação sumária das obras de Drummond e Mendes Campos, cabe realçar algumas afinidades estilísticas entre as crônicas: “Pelé, o Mágico” (2006, p. 95), do primeiro escritor e "Mané Garrincha” (2008, p. 28), do segundo. Ambas tratam, de forma poética e metalinguística, da essência da arte e da criação, aproximando o talentoso jogador de futebol do gênio e do mágico. Para tanto, pinçamos dois fragmentos metalinguísticos que aparecem nas crônicas. O primeiro, do texto de Drummond:

O difícil, o extraordinário, não é fazer mil gols, como Pelé. É fazer um gol como Pelé. [...]

Que adianta escrever mil livros, como simples resultado de aplicação mecânica, mãos batendo máquina de manhã à noite, [...]. O livro único, este não há condições, regras, receitas, códigos, cólicas que o façam existir, e só ele conta - negativamente - em nossa bibliografia. (2006, p. 195).

O segundo, do texto de Mendes Campos: “Como um poeta tocado por um anjo, como um compositor seguindo a melodia que lhe cai do céu, como um bailarino atrelado ao ritmo, Garrincha joga futebol por pura inspiração, por magia, [...]. Garrincha é como Rimbaud: gênio em estado nascente.” (2008, p. 28)

Como podemos ver, o fragmento da crônica de Drummond indica uma tomada de posição, uma espécie de autocrítica, em que o narrador afirma que cabe ao escritor cultivar sua arte, desde que esta não esteja impregnada de clichês e, por isso, aproximese de um gol de Pelé. Fica evidente o papel do crítico que defende uma arte reveladora, contrária à escrita mecânica. O juízo estético, o questionamento do senso comum, o papel do escritor, tudo isso vem à tona já nos primeiros parágrafos. Drummond aproxima um feito em campo, uma grande jogada, com uma obra literária fundamental.

Já na crônica de Mendes Campos, o narrador aproxima as performances de Garrincha a um poema, uma melodia, uma dança, enfim, como Drummond, a uma 
realização artística. Nota-se, no texto de Mendes Campos, o mesmo teor crítico e reflexivo de Drummond em relação aos julgamentos sociais. O narrador-autor de Mendes Campos, assumindo o papel de jornalista, afirma que escrevera sobre Garrincha e Pelé, embora estes não tivessem ainda reconhecimento. Utilizando-se da preterição, informa que não quer ser modesto, então, nega claramente o que afirma, pois nota-se que ele é, de fato, exibicionista: "Não quero ser modesto em matéria de futebol: descobri de imediato esse mundo novo - Garrincha - com a intuição alvoroçada de todas as alegrias que dele me viriam.” (2008, p. 26). Essa estratégia discursiva confere efeito de humor à crônica.

As crônicas de ambos enfocam, no mesmo contexto do final das décadas de 1950 e 1960, os costumes e as relações sociais que se estabelecem na cidade do Rio de Janeiro, no cenário carioca, justifica-se, então, o título deste artigo. Quanto à exploração de recursos linguísticos, observamos que os dois escritores aproximam seu texto da linguagem oral, configurando-os como um diálogo com o leitor. A presença da oralidade avulta no emprego da hipérbole, de gírias, neologismos e no uso da função conativa e emotiva da linguagem. No texto de Drummond, o narrador, por meio de uma reflexão metafísica e irônica, emprega tanto a primeira pessoa do plural, em uma estratégia discursiva na qual o leitor se sente incluído na enunciação, ou seja, contemplado como interlocutor, quanto a primeira pessoa do singular: "Então o gol independe de nossa vontade, formação e mestria? Receio que sim.” (2006, p. 195). Em Mendes Campos, essa inclusão do leitor na enunciação ocorre de forma mais descontraída, o narrador assume a primeira pessoa do singular, simulando uma conversa informal: "Há pouco tempo, um amigo meu, tricolor cordial, perguntou a Garrincha se era verdade que o clube dele era o Fluminense.” (2008, p. 26)

Ao tratar de forma específica da prosa de Drummond, Candido assinala que a prosa serviria para repassar a mesma matéria da poesia, mas com menor tensão. Segundo atesta, "A prosa de Drummond em geral distende o leitor e por isso é de excelente convívio. A sua poesia, ao contrário, força o leitor a se dobrar em torno de si mesmo como um punho fechado” (1993, p. 19). Para o estudioso:

A poesia é mais tensa, porque depende de uma exploração constante da multiplicidade de significados da palavra. Nela, cada palavra é e não é o que parece, e na escolha semântica predominante, efetuada pelo poeta, fervemos significados recalcados, de maneira a 
estabelecer com freqüência a dificuldade, a obscuridade essencial, solicitando a mobilização de todas as possibilidades de compreensão do leitor. (CANDIDO, 1993, p. 19).

Embora o livro Quando é dia de futebol esteja em prosa, deparamo-nos com um Drummond mais afinado, com um procedimento verbal mais “distendido” da crônica esportiva, uma prosa associada à concisão da linguagem jornalística, prática de “aperfeiçoamento”. Contudo, uma prosa que não se desliga da poesia, pois a menciona como parâmetro de excelência para a realização da arte, mesmo que futebolística: “A obra de arte, em forma de gol ou de texto, casa, pintura, som, dança e outras mais, parece antes coisa-em-ser na natureza, revelada arbitrariamente, quase que à revelia do instrumento humano usado para a revelação.” (2006, p. 195). Além de mencioná-la, apropria-se de seus recursos linguísticos, como a paronomásia nos termos: “revelada”, “revelia”, “revelação”, para afirmar que a genialidade, no futebol, acontece apesar do instrumento humano que a produz, ou seja, ela ultrapassa as limitações do homem. Pode-se notar que, tanto Drummond como Mendes Campos, ao conferirem lirismo ao gol, aproximam a magia do futebol à da literatura. Essa mesma arbitrariedade, presente na manifestação artística concebida como mágica, como feito milagroso, é apresentada pelo narrador de Mendes Campos, ao afirmar a espontaneidade e instinto de Garrincha: "Se um técnico desprovido de sensibilidade decide funcionar como cérebro de Garrincha, [...], pronto - é o fim. O grande mago perde a espontaneidade, [...]. Em vez do milagre, que ele sabe fazer, ensinam-lhe a fazer um truque sensato. Não pode haver maior tolice.” (2008, p. 28)

Como podemos notar, em ambas crônicas, os narradores, ao tratarem do futebol, revelam o "alumbramento" com o feito humano, sobretudo quando este se manifesta, na jogada, sob a forma de gol e dribles artísticos. Nesse instante, o homem se eleva, pois se aproxima do mágico e do divino, de santos e magos. O mesmo acontece com o grande escritor que, ao se revelar de forma magistral na produção literária, resgata a nossa essência divina, justamente, a que nos capacita à criação artística.

\section{Considerações finais}

Segundo Candido (1992), o prestígio da crônica advém do processo de busca da presença da oralidade na escrita, ou seja, da quebra do artifício e da aproximação com o 
que há de mais natural no modo de ser contemporâneo. Para o crítico, justamente, a simplicidade da crônica é o que a torna tão reveladora e penetrante para o leitor. As crônicas de Drummond e Mendes Campos revelam essa simplicidade, configurando-se como textos saborosos e dinâmicos. Essas crônicas, embora se apoiem em fatos, transformam a realidade do dia a dia, pela força da criatividade. Como privilegiam o acontecimento estético, sua linguagem passa a ser o fim e não o meio. Assim, diferem da crônica jornalística (policial, esportiva, social) que tem um caráter mais informativo e visam às notícias de maior impacto.

A subjetividade presente nas crônicas de ambos, própria do texto literário (MOISÉS, 2005), aproxima-as do texto lírico e instaura o diálogo com o leitor dentro de um processo natural. Seu estilo direto, espontâneo, de imediata apreensão e de forma despojada, explora a polissemia das metáforas. Os cronistas mantêm, como verificamos na análise, um diálogo virtual com o seu interlocutor. Neste diálogo, privilegia-se a reflexão crítica que, por sua vez, conduz o leitor implícito à ampliação de seus horizontes de expectativa. Em síntese, as crônicas de Drummond e Campos, justamente porque literárias, apresentam como característica a linguagem em sua potência máxima de sentidos. Esse diálogo com o leitor que elas instauram, assim como sua subjetividade, em um processo por meio do qual se privilegia a literariedade do texto, conduzem à reflexão acerca da realidade circundante, dos papéis sociais representados pelos sujeitos e do fazer literário.

Pela leitura das obras de ambos, sobretudo pela análise de suas crônicas, sentimo-nos como leitores considerados e contemplados no discurso, provocados por suas lacunas instauradas na ironia, na preterição, no emprego de figuras de linguagem diversas, no humor e na dialogia com autores diversos. A comunicabilidade presente em suas crônicas confere prazer ao leitor e promove sua emancipação, pois ao provocar-lhe o riso e despertar seu senso crítico acerca da realidade social, também, o conduz à reflexão sobre o fazer artístico. Essa reflexão advém de uma dupla admiração, ou seja, de um "alumbramento", provocado pelo reconhecer de grandes feitos humanos no meio de campo carioca. Estes, por sua vez, inspiram criações também artísticas, contudo, no meio do discurso literário de dois geniais mineiros. 


\section{Referências Bibliográficas}

ANDRADE, Carlos Drummond de. Quando é dia de futebol. Organizadores Luis M. G. Drummond \& Pedro A. G. Drummond. São Paulo: Record, 2006.

BAKHTIN, Mikhail. Marxismo e filosofia da linguagem: problemas fundamentais do Método Sociológico na Ciência da Linguagem. Trad. Michel Lahud; Yara F. Vieira. 7. ed. São Paulo: Hucitec, 1995.

BARROS, Diana P. de. "Dialogismo, polifonia e enunciação". In: ; FIORIN, José L. (orgs.). Dialogismo, polifonia, intertextualidade: em torno de Bakthin. São Paulo: Editora da Universidade de São Paulo, 1999, pp. 1-9.

BOURDIEU, Pierre. O poder simbólico. Trad. Fernando Tomaz. 7. ed. Rio de Janeiro: Bertrand Brasil, 2004.

CAMPOS, Paulo Mendes. O gol é necessário: crônicas esportivas. Org. Flávio Pinheiro. 4. ed. Rio de Janeiro: Civilização Brasileira, 2008.

CANDIDO, Antonio. “A vida ao rés-do-chão”. In: et al. A crônica: o gênero, sua fixação e suas transformações no Brasil. Campinas: Editora da UNICAMP; Rio de Janeiro: Fundação Casa de Rui Barbosa, 1992, pp. 13-22.

Letras, 1993. "Drummond prosador". In: Recortes. São Paulo, Companhia das

ECO, Umberto. Sobre literatura. Rio de Janeiro: Record, 2003.

ISER, Wolfgang. O ato da leitura: uma teoria do efeito estético. Trad. Johannes Kretschmer. São Paulo: Ed. 34, 1999.

MOISÉS, Massaud. A criação literária: prosa - II. 19. ed. São Paulo: Cultrix, 2005.

PIRES, Antonio D. “Considerações (intempestivas) sobre a prosa de Drummond”. In: Cerrados: Revista do Programa de Pós-Graduação em Literatura. Brasília (UnB), vol. 26, n. 1, p. 169-205, 2008.

PERRONE-MOISÉS, Leyla P. "Literatura comparada, intertexto e antropofagia”. In: Flores da escrivaninha. São Paulo: Companhia das Letras, 1990, p. 91-99.

RODRIGUES, Nelson A. D. Os estilos literários e letras de música popular brasileira. São Paulo: Arte \& Ciência, 2003.

SÁ, Jorge de. A crônica. 6. ed., 4. reimpr. São Paulo: Ática, 2002. 